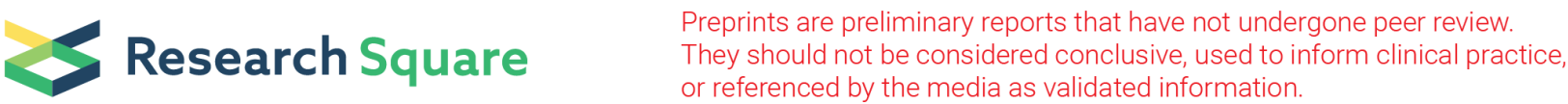

\section{Relationship between changes in serum myostatin and adiponectin in patients with obesity undergoing a weight loss program}

\section{Nana Takao ( $\nabla$ takaonan@hirakata.kmu.ac.jp )}

Kansai Medical University

\section{Satoshi Kurose}

Kansai Medical University

\section{Takumi Miyauchi}

Kansai Medical University

\section{Katsuko Onishi}

Kansai Medical University

Atsuko Tamanoi

Kansai Medical University Hospital

\section{Ryota Tsuyuguchi}

Kansai Medical University

Aya Fujii

Kansai Medical University

\section{Sawako Yoshiuchi}

Kansai Medical University Hospital

Kazuhisa Takahashi

Kansai Medical University

Hiromi Tsutsumi

Kansai Medical University

\section{Yutaka Kimura}

Kansai Medical University Hospital

\section{Research Article}

Keywords: body composition, lean mass, myostatin, adiponectin, weight loss

Posted Date: March 23rd, 2021

DOl: https://doi.org/10.21203/rs.3.rs-318321/v1

License: (9) This work is licensed under a Creative Commons Attribution 4.0 International License. Read Full License

Version of Record: A version of this preprint was published at BMC Endocrine Disorders on July 8th, 2021. See the published version at https://doi.org/10.1186/s12902-021-00808-4. 


\section{Abstract}

Background: Previously, we observed that adiponectin-an adipose tissue-derived hormone-was negatively correlated with muscle strength while myostatin-a myokine protein secreted by skeletal muscle-was positively correlated with appendicular lean mass. Albeit interesting, the relevance of these relationships is unclear. Thus, we aimed to examine the relationship between myostatin, adiponectin, and body composition in patients with obesity undergoing a weight loss program.

Methods: We studied 66 patients with obesity (age: $46.8 \pm 14.0$ years, body mass index: $34.3[31.0,38.4] \mathrm{kg} / \mathrm{m}^{2}$ ) attending a hospital for a weight loss program. Participants were divided into those with weight reduction less than $5 \%$ (the $L$ group) and greater than $5 \%$ (the $\mathrm{M}$ group) from the baseline. All patients underwent blood tests and were assessed for body composition, insulin resistance, adipocytokines, myokines, exercise tolerance, and muscle strength at baseline and after the program.

Results: Serum myostatin and adiponectin levels increased after the program in both groups. Body weight and \%fat decreased, and the rate of lean body mass (\% LBM) increased in both groups. Exercise capacity and muscle strength improved in the $M$ group only. Change in $(\Delta)$ myostatin correlated with $\Delta \%$ fat, $\Delta \% \mathrm{LBM}$, and $\Delta$ adiponectin. $\Delta$ adiponectin $(\beta=-0.262, \mathrm{p}=0.035)$ as an independent predictor of $\Delta$ myostatin.

Conclusions: Myostatin and adiponectin might crosstalk and regulate changes in skeletal muscle and fat mass. These findings might predict the effects of weight loss and prevent skeletal muscle mass loss by evaluating serum myostatin and adiponectin in clinical practice.

\section{Background}

People who are overweight and with obesity, which increases adipose tissue mass, are at major risk for chronic diseases, including diabetes, cardiovascular diseases, cancer, and decreased quality of life [1]. The ideal path to weight loss for people who are overweight and with obesity is reducing body fat mass while maintaining skeletal muscle mass.

Adipose tissue is a multifunctional organ. Adiponectin, an adipose tissue-derived hormone, improves insulin sensitivity and its levels of circulation are decreased in obesity-induced insulin resistance [2]. Adiponectin is an important adipocytokine as it protects against various diseases such as metabolic syndrome, type 2 diabetes, hypertension, and cardiovascular diseases associated with obesity [3,4]. It has anti-atherosclerotic and anti-inflammatory effects and is secreted from fat tissue [2]. Recent studies have found that skeletal muscle secretes adiponectin, which then acts as a signal to maintain skeletal muscle function and as a metabolic regulator. Adiponectin also responds to, and is mediated by, physical exercise, thereby affecting the skeletal muscle [5]. However, higher blood adiponectin levels are associated with lower muscle mass, lower limb muscle strength, and lower handgrip strength in the elderly [6,7]. These reports show that adiponectin acts as a conventional beneficial adipokine and has a relationship with skeletal muscle dysfunction. Skeletal muscle has recently been noted as an endocrine organ [8]. Myostatin, a member of the TGF- $\beta$ superfamily, is a myokine protein secreted by skeletal muscle, which acts in the inhibitory system of skeletal muscle formation. Myostatin inhibition contributes to reducing fat accumulation by increasing muscle mass and strength. Myostatin inhibition has improved insulin sensitivity in old mice $[9,10]$ and is proven to be beneficial for the treatment of several human diseases related to skeletal muscle wasting, such as chronic kidney disease, cancer, and heart failure [11]. Blood myostatin levels in patients with obesity have been associated with lower sugar metabolism [12]. It has also been reported that myostatin is expressed in adipose tissue and plays a key role in adipogenesis [13]. Some studies have shown a relationship between adiponectin or myostatin and weight loss, diet intervention, or exercise [14-19]. Diet-induced weight and body fat loss were associated with increased adiponectin concentrations in adults with obesity $[15,18]$. Additionally, a four-week hypocaloric diet and physical exercise program in people with severe obesity resulted in metabolic amelioration associated with a significant increase in adiponectin levels [19]. However, myostatin was reduced after six months of aerobic exercise in middle-aged men, even though their weight did not change [14]. Moreover, myostatin mRNA expression was significantly reduced with improved insulin sensitivity after a six-month aerobic exercise training program combined with modest weight loss in adults with obesity [16]. Simultaneously, previous research reported that plasma myostatin was not associated with weight loss in patients undergoing a non-surgical weight loss program [17]. 
Skeletal muscle mass often decreases with weight loss, and it is important to suppress this. Networks of adipose tissue and skeletal muscle may regulate skeletal muscle, and simultaneous examination of adiponectin and myostatin kinetics may inform an ideal weight loss approach. We previously reported that adiponectin was negatively correlated with muscle strength, and myostatin was positively correlated with appendicular lean mass [20]. The fact that there was a relationship between myostatin or adiponectin and body composition or muscle strength was interesting; however, the relevance of these relationships is unclear. There are no reports that have used longitudinal studies in clinical practice to assess both myostatin and adiponectin and their relationship with body composition in patients with obesity. Generally, successful weight loss in severe obesity is 5\% or more [21]. Secretory dynamics of myostatin and adiponectin, however, might differ because body fat and skeletal muscle mass change depending on the magnitude of weight loss. If these relationships can be understood, this may inform the planning of weight loss programs that reduce body fat mass while preventing the loss of skeletal muscle mass.

\section{Methods}

\section{Participants}

We studied 66 patients with obesity (body mass index $[\mathrm{BMI}] \geq 30$ ) who attended the obesity treatment program at the Health Science Center, Kansai Medical University Hospital, between October 2014 and October 2018. The exclusion criteria were BMI $\geq 60$, pregnancy, severe liver dysfunction, renal disease, secondary causes of obesity due to endocrine disorders, and debilitating disease.

Participants were divided into two groups: those with weight reduction less than $5 \%$ of the baseline were classified as the $L$ group; those with weight reduction more than $5 \%$ of the baseline were in the $\mathrm{M}$ group. Medical history and clinical characteristics were collected from medical records.

This study was approved by the ethics committee of the Kansai Medical University (approval no. 2019092). All procedures performed in the study involving human participants were performed in accordance with the 1964 Helsinki Declaration and its later amendments. Written informed consent was obtained from all participants prior to the commencement of the study.

\section{Obesity treatment program}

The program consisted of exercise, nutritional, and psychological counseling [20]. All patients had their blood tested and were assessed for body composition, insulin resistance, adipocytokine levels, exercise tolerance, and muscle strength (handgrip and lower limb muscle strength) at baseline and after six months. The exercise program consisted of 30 minutes of aerobic exercise, in which the intensity was adjusted to the anaerobic threshold, resistance training, and stretching at the hospital. Participants were also instructed to perform exercise three times per week for six months, including home exercise. Additionally, monthly nutrition guidance by a dietician and psychological counseling by a clinical psychologist were provided.

\section{Measurement of body composition}

Body composition was measured by dual-energy X-ray absorptiometry (DXA, DPX-NT System, GE Healthcare, Buckinghamshire, UK). The measurement parameters included weight, fat mass, and lean body mass (LBM) (whole body, upper extremities, body trunk, and lower extremities). The rates of fat mass (\%fat) and LBM (\%LBM) were calculated as fat mass and LBM divided by body weight, respectively. Visceral fat area (VFA) and subcutaneous fat area (SFA) at the umbilical level were measured using computed tomography and fat scan analysis software (East Japan Technology Tokyo Laboratory, Tokyo, Japan).

\section{Blood sampling and measurement of serum adipokine and myokine levels}

Medical history and clinical characteristics were collected from medical records. Fasting blood was analyzed to determine glucose (GLU), glycosylated hemoglobin (HbA1c), and immunoreactive insulin (IRI) levels, as well as lipid profiles (high-density lipoprotein cholesterol: HDL-C; low-density lipoprotein cholesterol: LDL-c; triglyceride: TG) and C-reactive protein (CRP). We evaluated the endogenous effect of insulin resistance on vascular function. Insulin resistance was assessed by the homeostasis model assessment of insulin resistance (HOMA-IR). HOMA-IR was calculated as follows: HOMA-IR = (IRI $\times$ fasting plasma glucose) $/ 405$. Additionally, we measured the plasma levels of myokines, adiponectin, leptin, and irisin. Blood samples were stored at $-80^{\circ} \mathrm{C}$, and 
both myokine and adipokine levels were measured according to the manufacturer's instructions. Serum myostatin and irisin levels as myokines were measured using the GDF-8/Myostatin Quantikine ELISA Kit (R\&D Systems, Minneapolis, MN, USA) and human EIA Kit (Phoenix Pharmaceuticals Inc., Burlingame, CA, USA). Serum adiponectin and leptin levels as adipokines were measured using the human Quantikine ELISA Kit (R\&D Systems, respectively. Minneapolis, MN, USA). The intra- and inter-assay coefficients of variation were $2.5 \%-4.7 \%$ and $5.8 \%-6.9 \%$ for adiponectin, $3.0 \%-3.3 \%$ and $3.5 \%-5.4 \%$ for leptin, $1.8 \%-5.4 \%$ and $3.6 \%-6.0 \%$ for myostatin, and $<10 \%$ and $<15 \%$ for irisin, respectively.

\section{Cardiopulmonary exercise test}

A symptom-limited exercise stress test, using the ramp method, was conducted using an expiration gas analyzer (AE300S, Minato Medical Science Co., Ltd., Osaka, Japan) and an ergometer cycle (AEROBIKE 75XL, Combi, Tokyo, Japan) with a 12-lead electrocardiogram. Exercise began with a four-minute warm-up at 10-20 W and $50 \mathrm{rpm}$, followed by the 10-20 W ramp method after a five-minute rest on the ergometer. Heart rate, oxygen uptake $\left(\mathrm{VO}_{2}\right)$, and carbon dioxide excretion volume $\left(\mathrm{VCO}_{2}\right)$ were measured at the point of rest, warm-up, anaerobic threshold (AT), and maximum oxygen uptake (peak $\left.\mathrm{VO}_{2}\right)$ using the breath-bybreath method. The AT was determined using the V-slope method. Peak $\mathrm{VO}_{2}$ and work rate were defined as the peak values during incremental exercise.

\section{Physical function}

Muscle strength and performance were measured using handgrip strength and lower limb muscle strength. Handgrip strength was measured with the help of a handgrip dynamometer (T.K.K.5401, Takei Scientific Instruments, Niigata, Japan). The grip strength of the right and left hands was measured three times each, and the mean measurement was recorded. Lower limb muscle strength was measured twice for isokinetic output torque using a recumbent ergometer (Strength Ergo, Mitsubishi Electric Corp., Tokyo, Japan). We recorded the maximum and divided values by body weight $(\mathrm{N} \bullet \mathrm{m} / \mathrm{kg})$.

\section{Arterial stiffness and endothelial function}

Brachial-ankle pulse wave velocity (baPWV) was measured as assessing arterial stiffness. baPWV was measured by using a pulse pressure analyzer (BP-203RPE, Omron Colin Co. Ltd., Japan) after 10 minutes of rest in the supine position. It was performed twice every two minutes and the mean value of the right and left arms was used as the final baPWV.

Endothelial function was analyzed after 10 minutes of rest in the supine position with an Endo-PAT2000 (Itamar Medical Co. Ltd., Israel). The reactive hyperemia index $(\mathrm{RHI})$ was measured based on a previous description [22]. Briefly, a blood pressure cuff was placed on the upper arm (research arm) and the contralateral arm served as a control (control arm). The reactive hyperemia peripheral arterial tonometry probe was placed on one finger of each hand. The cuff was inflated at $+60 \mathrm{mmHg}$ or higher or 200 $\mathrm{mmHg}$ for five minutes and was then deflated to induce reactive hyperemia.

\section{International physical activity questionnaire}

Physical activity was self-reported using a shortened version of the international physical activity questionnaire. The questionnaire was composed of seven questions assessing physical activity in the past week. Metabolic equivalent (MET) values for walking, average physical activity, and intense physical activity were computed as 3.3,4, and 8, respectively. The total amount of physical activity per week (day $\times$ minutexMET) was calculated by aggregating the amount of walking, moderate physical activity, and intense physical activity.

\section{Statistical analysis}

The measured values were expressed as mean \pm standard deviation or median ( $25 \%, 75 \%$ quartile), and categorical data were expressed as incidences and percentages. Changes $(\Delta)$ were calculated as differences between pre- and post-intervention. Normal distribution was confirmed using the Shapiro-Wilk test. An unpaired $t$-test, Mann-Whitney $U$ test, or Chi-squared test was used for inter-group comparisons. A paired $t$-test and Wilcoxon signed-rank test were used for pre- and post-comparisons. Correlations between myostatin and other parameters were determined using Pearson's or Spearman's rank correlation coefficient. A stepwise multiple regression analysis was used for multivariable analysis to examine independent predictors of $\Delta$ myostatin. The 
parameters of significant correlation with $\Delta$ myostatin were used as independent variables, and sex, age, and diabetes morbidity were used as adjustment factors. A p value of $<0.05$ was considered statistically significant. All statistical analyses were conducted using SPSS version 23.0 for Windows (IBM Corp., Armonk, NY, USA).

\section{Results}

\section{Baseline characteristics and parameter changes after obesity treatment in all participants}

The characteristics of all participants are presented in Table 1. The mean age of the patients was $46.8 \pm 14.0,18 \%$ were male, BMI was 34.3 (25\% quartile, $31.0 ; 75 \%$ quartile, 38.4$) \mathrm{kg} / \mathrm{m}^{2}$, and $24.2 \%$ of the participants had diabetes.

Changes in parameters from the baseline to after the obesity treatment program for all participants are shown in Table 2. BMI $\left(34.3(31.0,38.4)\right.$ to $\left.32.1(29.0,35.9) \mathrm{kg} / \mathrm{m}^{2}\right)$, \%fat $(45.3(40.8,49.8)$ to $43.6(38.5,49.5) \%)$, and \%LBM $(52.9(48.4,57.5)$ to 55.1 $(49.0,59.5) \%)$ were significantly decreased after the program. VFA, SFA, exercise capacity, leg strength, and physical activity also significantly improved. Fasting GLU, HbA1c, and lipid profiles, except for LDL-c, significantly improved after the program. The serum myostatin $(2,377.5(1,759.9,2926.3)$ to $2,502.3(2,209.7,3548.7) \mathrm{pg} / \mathrm{mL})$ and adiponectin $(2.87(1.68,4.24)$ to $4.22(2.98$, $6.05) \mu \mathrm{g} / \mathrm{mL}$ ) were significantly increased, and leptin and irisin levels significantly decreased after the program.

\section{Comparison of the baseline characteristics and parameter changes in the two groups}

Comparisons of the baseline characteristics and parameter changes after the obesity treatment program in the two groups are presented in Table 2. Program period, age, and sex were not significantly different between the two groups. A large number of participants with diabetes mellitus $(p<0.05)$ and hypertension $(p<0.01)$ were in the $L$ group. Fasting GLU was also significantly higher in the $L$ group $(p<0.01)$. However, there were no other significant differences between the groups before the program.

All the parameters of body composition, except VFA in the $L$ group, significantly improved in both groups. Exercise capacity and muscle strength were significantly improved in the M group but not in the L group. Fasting GLU and lipid profiles, except LDL-c, were significantly improved in the M group. Fasting insulin and HOMA-IR did not improve in either of the groups. Serum myostatin, adiponectin, leptin, and irisin changed significantly in both groups after the treatment program.

\section{Correlation of the changing \%LBM and myostatin with other parameters and stepwise multiple regression analysis of myostatin changes}

The correlation of the change in \%LBM, myostatin, and adiponectin with changes in the other parameters are presented in Table 3 . There were significant correlations between $\Delta \%$ LBM and $\Delta$ Weight $(r=-0.508, p<0.001), \Delta B M I(r=-0.484, p<0.001), \Delta \%$ fat $(r=$ -0.892, $p<0.001), \triangle$ VFA $(r=-0.363, p=0.003), \triangle \operatorname{SFA}(r=-0.519, p<0.001), \Delta$ peak VO $2(r=0.315, p=0.011)$, and $\Delta$ myostatin $(r=$ $-0.359, \mathrm{p}=0.003)$ (Figure 1). There was a significant correlation between $\Delta$ myostatin and $\Delta \%$ fat $(r=0.347, p=0.004), \Delta \%$ LBM $(r=-0.359, p=0.003)$, and $\Delta$ adiponectin $(r=-0.250, p=0.043) . \Delta$ adiponectin was significantly correlated with $\Delta$ handgrip $(r=$ $-0.253, \mathrm{p}=0.047)$ and $\Delta$ myostatin $(r=-0.250, \mathrm{p}=0.043)$.

Table 4 shows the forward-backward stepwise multivariate regression analysis for identifying the independent predictors of $\Delta$ myostatin. The independent variables examined for $\Delta$ myostatin were sex, age, diabetes, $\Delta \% \mathrm{fat}, \Delta \% \mathrm{LBM}$, and $\Delta$ adiponectin based on the significance of the univariate analysis. Stepwise multiple regression analysis identified $\Delta$ adiponectin $(\beta=-0.262, p=$ 0.035) as an independent predictor of the changing myostatin factors.

\section{Discussion}

This is the first report that used longitudinal studies in clinical practice to assess both myostatin and adiponectin and their relationship with body composition in patients with obesity undergoing a weight loss program. The mean weight loss was $7.5 \%$ and body composition, exercise capacity, and leg strength were improved after the obesity treatment program for about six months in all participants. Serum myostatin and adiponectin levels increased after the program. We also found that myostatin and adiponectin were significantly increased with or without $5 \%$ weight loss, but there were no significant differences between the 
groups. Moreover, changes in LBM/body weight and serum adiponectin were correlated with changes in serum myostatin. Furthermore, change in the serum adiponectin level was an independent predictor of the change in serum myostatin. Therefore, our study suggests that serum myostatin and adiponectin might be in control of each other and affect the changes in body composition.

Serum adiponectin was significantly increased after treatment in all participants in this study, which is consistent with the results of recent studies $[15,18,19,23]$. However, although serum myostatin decreased or did not change after the weight maintenance program and exercise in recent studies $[14,16,17,24]$, it increased after weight loss in our study. We also analyzed differences in parameters between less or more than $5 \%$ weight loss and showed that serum myostatin levels significantly increased after weight loss in both groups, regardless of the weight loss amount. In our previous cross-sectional study, it was reported that serum myostatin was positively correlated with skeletal muscle/body weight, not absolute skeletal muscle mass [25]. This result means that myostatin is usually controlled by skeletal muscle mass per body weight to prevent overgrowth of skeletal muscle. In the present longitudinal study, the change in myostatin was negatively associated with changes in skeletal muscle indicators; therefore, it is important to suppress the increase in myostatin to prevent the loss of skeletal muscle mass in a weight loss program. In other words, we evaluated the serum myostatin level before and after weight loss treatment and observed that the relationship between changes in body composition during treatment may inform optimal weight loss treatment strategies, such as preventing loss of skeletal muscle mass and decreasing body fat mass.

We hypothesized that changes in myostatin and adiponectin would affect the degree of weight loss, but there was no relationship between myostatin, adiponectin, and weight loss. Therefore, we analyzed the relationship between myostatin, adiponectin, and the rate of LBM divided by body weight using all data. Changes in myostatin levels were also negatively correlated with changes in adiponectin levels in our study. Additionally, we found that change in adiponectin was an independent predictor of the change in myostatin. Changes in myostatin and adiponectin by weight loss might be interrelated, and myostatin might have influenced the change in LBM/body weight. Adiponectin, an important adipocytokine produced mainly by adipocytes, protects against a variety of obesity-related medical conditions. Adiponectin is inversely correlated with obesity and is tightly regulated at the transcriptional and translational levels. Myostatin has a tremendous impact on the growth and development of skeletal muscle, such that genetic deletions or mutations in the myostatin gene cause a dramatic increase in skeletal muscle mass and a decrease in fat mass [26]. Adiponectin works in concert with other important hormones including insulin, leptin, and various cytokines [27], and certain myokines and adipokines interact with each other [28]. However, the crosstalk between myostatin and adiponectin has not been clarified. There have been some reports on myostatin and adiponectin [29,30]; recent data suggested crosstalk between myostatininduced Smad2/3 and adiponectin-induced AMP-activated kinase/peroxisome proliferator-activated receptor a pathways [29]. Another study showed that myostatin affects adipocyte formation both in vitro and in vivo in mice [30]. Although the mechanism of the relationship between myostatin and adiponectin was unclear in our study, these recent reports help in understanding the mechanism of our results. It is necessary to suppress the myostatin secretion to prevent loss of skeletal muscle mass by weight loss treatment. Reducing or suppressing the increase in myostatin secretion is expected to contribute to the increase in energy expenditure by preventing skeletal muscle atrophy, leading to the enhancement of secondary fat metabolism and changes in systemic fat and glucose metabolism. As a result, the adiponectin secretion increased, and it was suggested that the changes in myostatin and adiponectin levels showed a negative correlation in this study. The advantage of our study was that it demonstrated that myostatin and adiponectin showed potential crosstalk from clinical data and might affect lean mass in obesity with a weight loss program. These findings might be informative in creating an optimal weight loss program by evaluating serum myostatin and adiponectin in clinical practice.

This study has several limitations. First, sex differences were not considered. A recent study showed that the serum myostatin level was elevated in male patients compared to female patients [12]. Plasma adiponectin levels are also affected by sex and age in rats [31]. We would have obtained more detailed information about myostatin and adiponectin related to the effect of body weight by examining sex separately; however, sex was included as an independent variable in the multivariate analysis in this study. Second, we could not use the nutrition data, the Food Frequency Questionnaire, because the data were often missing and could not be validated. Nutrition data are important for weight loss, and there are various reports about the relationship between myostatin and food intake [32,33]. One study found that there were no significant diet-related differences in the plasma levels of myostatin in insulin sensitivity of rats [32]. However, increased myostatin expression was demonstrated in muscle following high- 
fat diet intake in high-fat diet-induced obesity-susceptible mice, while myostatin expression levels decreased initially in muscle from high-fat diet-fed resistant mice [33]. Adiponectin exerts regulatory effects on glucose and lipid metabolism, insulin sensitivity, and inflammation. It plays an important role in the central regulation of appetite and eating behavior [34]. Food intake investigation might be important to demonstrate the relationship between myostatin, adiponectin, and weight loss. Finally, myostatin and adiponectin particular secretion levels in the skeletal muscle and adipose tissue are not clear because we measured their levels from blood samples. However, it is thought that evaluation with blood samples is useful for clinical application because it is assumed that biopsy of skeletal muscle and adipose tissue of patients is invasive.

\section{Conclusion}

This study showed that changes in serum myostatin were associated with changes in the rate of LBM and adiponectin. Additionally, change in adiponectin level was an independent predictor of change in myostatin. Therefore, myostatin and adiponectin might crosstalk and regulate changes in skeletal muscle and fat mass. These findings might be informative in predicting the effects of weight loss, and in preventing the loss of skeletal muscle mass by evaluating serum myostatin and adiponectin in clinical practice.

\section{List Of Abbreviations}

AT, Anaerobic threshold; baPWV, Brachial-ankle pulse wave velocity; BMI, Body mass index; CRP, C-reactive protein; GLU, Glucose; HbA1c, Glycosylated hemoglobin; HDL-c, High-density lipoprotein cholesterol; HOMA-IR, Homeostasis model assessment of insulin resistance; IRI, Immunoreactive insulin; LBM, Lean body mass; LDL-c, Low-density lipoprotein cholesterol; MET, Metabolic equivalent; RHI, Reactive hyperemia index; SFA, Subcutaneous fat area; $\mathrm{TG}$, triglyceride; $\mathrm{VCO}_{2}$, Carbon dioxide excretion volume; VFA, Visceral fat area; $\mathrm{VO}_{2}$, Oxygen uptake

\section{Declarations}

Ethics approval and consent to participate: This study was approved by the ethics committee of the Kansai Medical University (approval no. 2019092). All procedures performed in the study involving human participants were performed in accordance with the 1964 Helsinki Declaration and its later amendments. Written informed consent was obtained from the patient before undergoing all clinical procedures.

Consent for publication: Not applicable.

Availability of data and materials: The data that support the findings of this study are available on request from the corresponding author.

Competing interests: The authors declare that they have no competing interests.

Funding: This work was supported by the Japan Society for the Promotion of Science (JSPS), KAKENHI (Grant Number JP19K20026).

Authors' contributions: NT, SK, RT, AF, SY, HT, and YK contributed to the design of the study. TM, AT, AF, SY, KT, and YK contributed to research implementation. KO and AT contributed to data acquisition. NT and KO contributed to data correction. NT, SK, and YK analyzed the data and wrote the main manuscript text. All authors have read and approved the final manuscript.

Acknowledgments: We thank the staff members of the Health Science Center of Kansai Medical University.

\section{References}

1 Hruby A, Hu FB. The epidemiology of obesity: a big picture. Pharmacoeconomics. 2015;33:673-89. doi:10.1007/s40273014-0243-x. 
2 Rajala MW, Scherer PE. Minireview: the adipocyte-at the crossroads of energy homeostasis, inflammation, and atherosclerosis. Endocrinology. 2003;144:3765-73. doi:10.1210/en.2003-0580.

3 Kubota N, Terauchi Y, Yamauchi T, Kubota T, Moroi M, Matsui J, et al. Disruption of adiponectin causes insulin resistance and neointimal formation. J Biol Chem. 2002;277:25863-6. doi:10.1074/jbc.C200251200.

4 Nawrocki AR, Rajala MW, Tomas E, Pajvani UB, Saha AK, Trumbauer ME, et al. Mice lacking adiponectin show decreased hepatic insulin sensitivity and reduced responsiveness to peroxisome proliferator-activated receptor gamma agonists. J Biol Chem. 2006;281:2654-60. doi:10.1074/jbc.M505311200.

$5 \quad$ Krause MP, Milne KJ, Hawke TJ. Adiponectin-consideration for its role in skeletal muscle health. Int J Mol Sci. 2019;20:1528. doi:10.3390/ijms20071528.

6 Bucci L, Yani SL, Fabbri C, Bijlsma AY, Maier AB, Meskers CG, et al. Circulating levels of adipokines and IGF-1 are associated with skeletal muscle strength of young and old healthy subjects. Biogerontology. 2013;14:261-72. doi:10.1007/s10522-013-94285.

7 Huang C, Tomata Y, Kakizaki M, Sugawara Y, Hozawa A, Momma H, et al. High circulating adiponectin levels predict decreased muscle strength among older adults aged 70 years and over: a prospective cohort study. Nutr Metab Cardiovasc Dis. 2015;25:594-601. doi:10.1016/j.numecd.2015.03.010.

8 Giudice J, Taylor JM. Muscle as a paracrine and endocrine organ. Curr Opin Pharmacol. 2017:34:49-55. doi:10.1016/j.coph.2017.05.005.

9 Camporez JP, Petersen MC, Abudukadier A, Moreira GV, Jurczak MJ, Friedman G, et al. Anti-myostatin antibody increases muscle mass and strength and improves insulin sensitivity in old mice. Proc Natl Acad Sci. 2016;113:2212-7. doi:10.1073/pnas.1525795113.

10 Dong J, Dong Y, Dong Y, Chen F, Mitch WE, Zhang L. Inhibition of myostatin in mice improves insulin sensitivity via irisinmediated cross talk between muscle and adipose tissues. Int J Obes (Lond). 2016;40:434-42. doi:10.1038/ijo.2015.200.

11 Cohen S, Nathan JA, Goldberg AL. Muscle wasting in disease: molecular mechanisms and promising therapies. Nat Rev Drug Discov. 2015;14:58-74. doi:10.1038/nrd4467.

12 Tanaka M, Masuda S, Yamakage H, Inoue T, Ohue-Kitano R, Yokota S, et al. Role of serum myostatin in the association between hyperinsulinemia and muscle atrophy in Japanese obese patients. Diabetes Res Clin Pract. 2018;142:195-202. doi:10.1016/j.diabres.2018.05.041.

13 Deng B, Zhang F, Wen J, Ye S, Wang L, Yang Y, et al. The function of myostatin in the regulation of fat mass in mammals. Nutr Metab (Lond). 2017;14:29. doi:10.1186/s12986-017-0179-1.

14 Hittel DS, Axelson M, Sarna N, Shearer J, Huffman KM, Kraus WE. Myostatin decreases with aerobic exercise and associates with insulin resistance. Med Sci Sports Exerc. 2010;42:2023-9. doi:10.1249/MSS.0b013e3181e0b9a8.

15 Summer SS, Brehm BJ, Benoit SC, D'Alessio DA. Adiponectin changes in relation to the macronutrient composition of a weight-loss diet. Obesity (Silver Spring). 2011;19:2198-204. doi:10.1038/oby.2011.60.

16 Ryan AS, Li G, Blumenthal JB, Ortmeyer HK. Aerobic exercise + weight loss decreases skeletal muscle myostatin expression and improves insulin sensitivity in older adults. Obesity (Silver Spring). 2013;21:1350-6. doi:10.1002/oby.20216.

17 Tsioga MN, Oikonomou D, Vittas S, Kalscheuer H, Roeder E, Wintgens KF, et al. Plasma myostatin is only a weak predictor for weight maintenance in obese adults. Exp Clin Endocrinol Diabetes. 2015;123:466-72. doi:10.1055/s-0035-1559663.

18 Ma W, Huang T, Zheng Y, Wang M, Bray GA, Sacks FM, et al. Weight-loss diets, adiponectin, and changes in cardiometabolic risk in the 2-year POUNDS Lost Trial. J Clin Endocrinol Metab. 2016;101:2415-22. doi:10.1210/jc.2016-1207. 

people with severe obesity undergone a hypocaloric diet and physical exercise program. Nutrients. 2019;11:2195. doi:10.3390/nu11092195.

20 Kurose S, Tsutsumi H, Yamanaka Y, Shinno H, Miyauchi T, Tamanoi A, et al. Improvement in endothelial function by lifestyle modification focused on exercise training is associated with insulin resistance in obese patients. Obes Res Clin Pract. 2014;8:e106-14. doi:10.1016/j.orcp.2012.10.005.

21 Japan Society for the Study of Obesity. Guidelines for the Management of Obesity disease 2016. Tokyo: Life Science Co. Ltd.; 2016. p. 57-70.

22 Bonetti PO, Barsness GW, Keelan PC, Schnell TI, Pumper GM, Kuvin JT, et al. Enhanced external counterpulsation improves endothelial function in patients with symptomatic coronary artery disease. J Am Coll Cardiol. 2003;41:1761-8. doi:10.1016/s07351097(03)00329-2.

23 Campos RMDS, Masquio DCL, Corgosinho FC, Carvalho-Ferreira JP, Molin Netto BD, Clemente APG, et al. Relationship between adiponectin and leptin on osteocalcin in obese adolescents during weight loss therapy. Arch Endocrinol Metab.

2018;62:275-84. doi:10.20945/2359-3997000000039.

24 Allen DL, Hittel DS, McPherron AC. Expression and function of myostatin in obesity, diabetes, and exercise adaptation. Med Sci Sports Exer. 2016;43:1828-35. doi:10.1249/MSS.0b013e3182178bb4.

25 Kurose S, Onishi K, Takao N, Miyauchi T, Takahashi K, Kimura Y. Association of serum adiponectin and myostatin levels with skeletal muscle in patients with obesity: A cross-sectional study. PLoS One. 2021;16: e0245678.

doi:10.1371/journal.pone.0245678.

26 Sharma M, McFarlane C, Kambadur R, Kukreti H, Bonala S, Srinivasan S. Myostatin: expanding horizons. IUBMB Life. 2015;67:589-600. doi:10.1002/iub.1392.

27 Parida S, Siddharth S, Sharma D. Adiponectin, obesity, and cancer: Clash of the bigwigs in health and disease. Int J Mol Sci. 2019;20:E2519. doi:10.3390/ijms20102519.

28 Li F, Li Y, Duan Y, Hu CA, Tang Y, Yin Y. Myokines and adipokines: Involvement in the crosstalk between skeletal muscle and adipose tissue. Cytokine Growth Factor Rev. 2017;33:73-82. doi:10.1016/j.cytogfr.2016.10.003.

29 Liu XH, Pan JP, Bauman WA, Cardozo CP. AdipoRon prevents myostatin-induced upregulation of fatty acid synthesis and downregulation of insulin activity in a mouse hepatocyte line. Physiol Rep. 2019;7:e14152. doi:10.14814/phy2.14152.

30 Feldman BJ, Streeper RS, Farese RV Jr, Yamamoto KR. Myostatin modulates adipogenesis to generate adipocytes with favorable metabolic effects. Proc Natl Acad Sci U S A. 2006;103:15675-80. doi:10.1073/pnas.0607501103.

31 Quirós Cognuck S, Reis WL, Silva M, Debarba LK, Mecawi AS, de Paula FJA, et al. Sex differences in body composition, metabolism-related hormones, and energy homeostasis during aging in Wistar rats. Physiol Rep. 2020;8:e14597. doi:10.14814/phy2.14597.

32 Sharma N, Castorena CM, Cartee GD. Greater insulin sensitivity in calorie restricted rats occurs with unaltered circulating levels of several important myokines and cytokines. Nutr Metab (Lond). 2012;9:90. doi:10.1186/1743-7075-9-90.

33 Lyons JA, Haring JS, Biga PR. Myostatin expression, lymphocyte population, and potential cytokine production correlate with predisposition to high-fat diet induced obesity in mice. PLoS One. 2010;5:e12928. doi:10.1371/journal.pone.0012928.

34 Ma W, Huang T, Heianza Y, Wang T, Sun D, Tong J, et al. Genetic variations of circulating adiponectin levels modulate changes in appetite in response to weight-loss diets. J Clin Endocrinol Metab. 2017;102:316-25. doi:10.1210/jc.2016-2909. 


\section{Tables}

Table 1. Participants' clinical characteristics and parameter changes from pre- to post-obesity treatment program

\begin{tabular}{|c|c|c|c|c|}
\hline & & Pre & Post & $P$ value \\
\hline Age & years & $46.8 \pm 14.0$ & & \\
\hline Sex & $\mathrm{M} / \mathrm{F}(\%)$ & $18(27.3) / 48(72.7)$ & & \\
\hline Period & days & $199.8 \pm 23.1$ & & \\
\hline \multicolumn{5}{|l|}{ Coronary risk factors } \\
\hline Diabetes mellitus & $\mathrm{n}(\%)$ & $16(24.2)$ & & \\
\hline Hypertension & n (\%) & $30(45.5)$ & & \\
\hline Dyslipidemia & n (\%) & $19(28.8)$ & & \\
\hline Alcohol consumption & $\mathrm{n}(\%)$ & $29(43.9)$ & & \\
\hline Current smoker & n (\%) & $5(7.6)$ & & \\
\hline Exercise habits & n (\%) & $21(31.8)$ & & \\
\hline \multicolumn{5}{|l|}{ Body composition } \\
\hline Weight & $\mathrm{kg}$ & $90.2(78.5,102.3)$ & $85.1(73.8,96.4)$ & $<0.001$ \\
\hline BMI & $\mathrm{kg} / \mathrm{m}^{2}$ & $34.3(31.0,38.4)$ & $32.1(29.0,35.9)$ & $<0.001$ \\
\hline$\%$ fat & $\%$ & $45.3(40.8,49.8)$ & $43.6(38.5,49.5)$ & $<0.001$ \\
\hline$\%$ LBM & $\%$ & $52.9(48.4,57.5)$ & $55.1(49.0,59.5)$ & $<0.001$ \\
\hline Lean mass/fat mass & $\mathrm{kg} / \mathrm{kg}$ & $128.0 \pm 36.4$ & $148.8 \pm 78.8$ & $<0.001$ \\
\hline VFA & $\mathrm{cm}^{3}$ & $183.0 \pm 52.7$ & $158.3 \pm 63.5$ & $<0.001$ \\
\hline SFA & $\mathrm{cm}^{3}$ & $419.5 \pm 161.5$ & $374.9 \pm 160.3$ & $<0.001$ \\
\hline \multicolumn{5}{|c|}{ Exercise capacity and muscle strength } \\
\hline $\mathrm{ATVO}_{2}$ & $\mathrm{ml} / \mathrm{kg} / \mathrm{min}$ & $11.2(9.8,12.5)$ & $11.7(10.4,13.1)$ & 0.002 \\
\hline Peak $\mathrm{VO}_{2}$ & $\mathrm{ml} / \mathrm{kg} / \mathrm{min}$ & $18.0(15.5,20.3)$ & $19.6(16.2,23.2)$ & $<0.001$ \\
\hline Handgrip & $\mathrm{kg}$ & $26.4(20.2,30.5)$ & $26.2(20.9,32.0)$ & 0.214 \\
\hline Leg strength & $\mathrm{N} \cdot \mathrm{m} / \mathrm{kg}$ & $1.47 \pm 0.32$ & $1.53 \pm 0.39$ & $<0.001$ \\
\hline Physical activity & $\mathrm{kcal} / \mathrm{day}$ & $55.1(21.4,151.1)$ & $173.9(90.0,300.6)$ & 0.004 \\
\hline \multicolumn{5}{|c|}{ Arterial stiffness and endothelial function } \\
\hline baPWV & $\mathrm{m} / \mathrm{s}$ & $1,383.5 \pm 216.8$ & $1,336.8 \pm 243.4$ & 0.004 \\
\hline RHI & & $1.83(1.54,2.37)$ & $1.91(1.57,2.45)$ & 0.387 \\
\hline \multicolumn{5}{|l|}{ Blood sample } \\
\hline Fasting GLU & $\mathrm{mg} / \mathrm{dL}$ & $97(89.8,106.3)$ & $95(88.0,100.5)$ & 0.024 \\
\hline $\mathrm{HbA1c}$ & $\%$ & $5.8(5.6,6.3)$ & $5.6(5.4,6.0)$ & $<0.001$ \\
\hline Fasting insulin & $\mu \mathrm{U} / \mathrm{mL}$ & $14.6(9.2,19.4)$ & $12.1(8.5,21.9)$ & 0.904 \\
\hline HOMA-IR & & $3.4(2.1,4.8)$ & $2.9(1.9,5.2)$ & 0.546 \\
\hline HDL-c & $\mathrm{mg} / \mathrm{dL}$ & $44.0 \pm 10.5$ & $51.4 \pm 11.8$ & $<0.001$ \\
\hline LDL-C & $\mathrm{mg} / \mathrm{dL}$ & $115.1 \pm 29.4$ & $119.1 \pm 29.8$ & 0.053 \\
\hline TG & $\mathrm{mg} / \mathrm{dL}$ & $114.5(81.3,154.8)$ & $97.5(68.8,129.5)$ & 0.003 \\
\hline CRP & $\mathrm{mg} / \mathrm{dL}$ & $0.174(0.070,0.431)$ & $0.109(0.050,0.283)$ & 0.002 \\
\hline Myostatin & $\mu \mathrm{g} / \mathrm{mL}$ & $2,377.5(1,759.9,2,926.3)$ & $2,502.3(2,209.7,3,548.7)$ & $<0.001$ \\
\hline Adiponectin & $\mathrm{pg} / \mathrm{mL}$ & $2.87(1.68,4.24)$ & $4.22(2.98,6.05)$ & $<0.001$ \\
\hline Leptin & $\mathrm{ng} / \mathrm{mL}$ & $22.7(15.4,36.3)$ & $14.5(8.0,23.9)$ & $<0.001$ \\
\hline Irisin & $\mathrm{ng} / \mathrm{mL}$ & $23.2(19.5,27.7)$ & $17.6(16.7,18.7)$ & $<0.001$ \\
\hline
\end{tabular}

Note: Results are expressed as mean \pm standard deviation or median (25\%, $75 \%$ quartile).

M, male; F, female; BMI, body mass index; \%fat, fat mass/weight $\times 100$; \%LBM, lean body mass/weight $\times$ 100; VFA, visceral fat area; SFA, subcutaneous fat area; $\mathrm{AT}$, anaerobic threshold; $\mathrm{VO}_{2}$, oxygen consumption; 
baPWV, brachial-ankle pulse wave velocity; RHI, reactive hyperemia index; GLU, glucose; HbA1c, hemoglobin Alc; IRI, immunoreactive insulin; HOMA-IR, homeostasis model assessment-insulin resistance; HDL-c, highdensity lipoprotein cholesterol; LDL-c, low-density lipoprotein cholesterol; TG, triglyceride; CRP, C-reactive protein.

Table 2. Parameter changes from baseline to after weight reduction intervention in the two groups 


\begin{tabular}{|c|c|c|c|c|c|c|c|}
\hline & \multicolumn{2}{|c|}{ L group $(n=22)$} & \multicolumn{4}{|c|}{ M group (n=44) } \\
\hline & & \multirow{2}{*}{$\begin{array}{c}\text { Pre } \\
204.1 \pm 18.6\end{array}$} & \multicolumn{2}{|l|}{ Post } & \multirow{2}{*}{$\begin{array}{c}\text { Pre } \\
197.6 \pm 24.9\end{array}$} & Post & \\
\hline Period & days & & & & & & \\
\hline Age & years & $49.1 \pm 14.3$ & & & $45.7 \pm 14.0$ & & \\
\hline Sex & $\mathrm{M} / \mathrm{F}(\%)$ & $\begin{array}{l}5(22.7) / 17 \\
(77.3)\end{array}$ & & & $\begin{array}{l}14(31.8) / 30 \\
(68.2)\end{array}$ & & \\
\hline $\begin{array}{l}\text { Diabetes } \\
\text { mellitus }\end{array}$ & n (\%) & $9(40.9)$ & & & $7(15.9)^{*}$ & & \\
\hline Hypertension & n (\%) & $15(68.2)$ & & & $15(34.1)^{* *}$ & & \\
\hline Dyslipidemia & n (\%) & $5(22.7)$ & & & $14(31.8)$ & & \\
\hline $\begin{array}{l}\text { Body } \\
\text { composition }\end{array}$ & & & & & & & \\
\hline Weight & $\mathrm{kg}$ & $\begin{array}{l}86.7(77.9, \\
103.4)\end{array}$ & $\begin{array}{l}84.9(75.6, \\
104.2)\end{array}$ & 0.001 & $95.6 \pm 15.3$ & $84.4 \pm 14.6$ & $<0.001$ \\
\hline BMI & $\mathrm{kg} / \mathrm{m}^{2}$ & $35.6 \pm 6.7$ & $34.9 \pm 6.9$ & 0.002 & $\begin{array}{l}34.5(31.2, \\
38.4)\end{array}$ & $\begin{array}{l}31.7(28.3 \\
34.8)\end{array}$ & $<0.001$ \\
\hline \%fat & $\%$ & $44.8 \pm 6.5$ & $43.9 \pm 6.5$ & 0.010 & $44.9 \pm 6.5$ & $41.9 \pm 8.8$ & $<0.001$ \\
\hline \%LBM & $\%$ & $53.5 \pm 6.2$ & $54.4 \pm 6.1$ & 0.006 & $53.2 \pm 6.1$ & $56.4 \pm 8.2$ & $<0.001$ \\
\hline VFA & $\mathrm{cm}^{3}$ & $186.6 \pm 47.0$ & $181.6 \pm 69.5$ & 0.211 & $181.3 \pm 55.8$ & $146.7 \pm 57.6$ & $<0.001$ \\
\hline SFA & $\mathrm{cm}^{3}$ & $422.3 \pm 190.8$ & $402 \pm 178.8$ & 0.021 & $418.0 \pm 147.0$ & $361.2 \pm 150.5$ & $<0.001$ \\
\hline \multicolumn{8}{|c|}{ Exercise capacity and muscle strength } \\
\hline $\mathrm{ATVO}_{2}$ & $\mathrm{ml} / \mathrm{kg} / \mathrm{min}$ & $11.0 \pm 1.6$ & $11.3 \pm 1.9$ & 0.315 & $\begin{array}{l}11.4(9.8, \\
12.5)\end{array}$ & $\begin{array}{l}11.8(10.8 \\
13.5)\end{array}$ & 0.002 \\
\hline PeakVO $_{2}$ & $\mathrm{ml} / \mathrm{kg} / \mathrm{min}$ & $17.4 \pm 3.3$ & $17.6 \pm 3.9$ & 0.618 & $\begin{array}{l}18.3(15.7, \\
20.4)\end{array}$ & $\begin{array}{l}20.5(17.7 \\
23.9)\end{array}$ & $<0.001$ \\
\hline Handgrip & $\mathrm{Kg}$ & $26.0 \pm 7.1$ & $24.4 \pm 7.9$ & 0.293 & $26.5 \pm 9.0$ & $28.1 \pm 7.5$ & 0.032 \\
\hline $\begin{array}{c}\text { Leg } \\
\text { strength }\end{array}$ & $\mathrm{N} \bullet \mathrm{m} / \mathrm{kg}$ & $1.48 \pm 0.27$ & $1.45 \pm 0.34$ & 0.837 & $1.46 \pm 0.34$ & $1.56 \pm 0.41$ & $<0.001$ \\
\hline $\begin{array}{l}\text { Physical } \\
\text { activity }\end{array}$ & $\mathrm{kcal} /$ day & $\begin{array}{l}99.0(14.3 \\
274.3)\end{array}$ & $\begin{array}{l}139.3(26.8 \\
219.6)\end{array}$ & 0.575 & $\begin{array}{l}53.6(21.4, \\
120.0)\end{array}$ & $\begin{array}{l}198.0(107.1, \\
353.6)\end{array}$ & 0.002 \\
\hline \multicolumn{8}{|c|}{ Arterial stiffness and endothelial function } \\
\hline baPWV & $\mathrm{m} / \mathrm{s}$ & $1,429.6 \pm 243.1$ & $1,378.5 \pm 303.6$ & 0.053 & $1,360.4 \pm 201.4$ & $1,316.0 \pm 207.9$ & 0.033 \\
\hline RHI & & $\begin{array}{l}1.80 \\
2.58)\end{array}$ & $2.23(1.66,2.26)$ & 0.099 & $\begin{array}{l}1.83(1.54 \\
2.28)\end{array}$ & $\begin{array}{l}1.82(1.51 \\
2.45)\end{array}$ & 0.957 \\
\hline \multicolumn{8}{|l|}{ Blood sample } \\
\hline $\begin{array}{l}\text { Fasting } \\
\text { GLU }\end{array}$ & $\mathrm{mg} / \mathrm{dL}$ & $104.5 \pm 12.4$ & $102.9 \pm 16.3$ & 0.586 & $\begin{array}{l}95.5(87.0 \\
102.8)^{* *}\end{array}$ & $\begin{array}{l}94.0(87.3 \\
97.8)\end{array}$ & 0.047 \\
\hline $\mathrm{HbA1c}$ & $\%$ & $6.0(5.6,6.3)$ & $6.0(5.5,6.2)$ & 0.757 & $5.8(5.5,6.1)$ & $5.6(5.4,5.8)$ & $<0.001$ \\
\hline $\begin{array}{l}\text { Fasting } \\
\text { insulin }\end{array}$ & $\mu \mathrm{U} / \mathrm{mL}$ & $\begin{array}{l}14.9(8.5, \\
17.9)\end{array}$ & $11.4(8.5,22.0)$ & 0.270 & $\begin{array}{l}14.3(9.6, \\
19.7)\end{array}$ & $\begin{array}{l}12.6(8.0 \\
20.8)\end{array}$ & 0.436 \\
\hline HOMA-IR & & $3.5(2.3,4.6)$ & $2.9(2.0,5.7)$ & 0.372 & $3.4(2.0,5.0)$ & $2.9(1.8,5.0)$ & 0.165 \\
\hline HDL-C & $\mathrm{mg} / \mathrm{dL}$ & $45.9 \pm 12.9$ & $53.1 \pm 13.0$ & $\mathrm{p}<0.001$ & $43.0 \pm 9.0$ & $50.5 \pm 11.3$ & $<0.001$ \\
\hline LDL-c & $\mathrm{mg} / \mathrm{dL}$ & $107.8 \pm 21.0$ & $115.4 \pm 24.7$ & 0.014 & $118.7 \pm 32.4$ & $121.0 \pm 32.1$ & 0.407 \\
\hline TG & $\mathrm{mg} / \mathrm{dL}$ & $119.1 \pm 43.8$ & $96.9 \pm 43.4$ & 0.032 & $\begin{array}{l}115.0(78.0 \\
158.5)\end{array}$ & $\begin{array}{l}94.5(68.3 \\
140.8)\end{array}$ & 0.024 \\
\hline $\mathrm{CRP}$ & $\mathrm{mg} / \mathrm{dL}$ & $\begin{array}{l}0.175(0.095 \\
0.440)\end{array}$ & $\begin{array}{l}0.130(0.054 \\
0.251)\end{array}$ & 0.033 & $\begin{array}{l}0.163(0.049 \\
0.440)\end{array}$ & $\begin{array}{l}0.108(0.035 \\
0.340)\end{array}$ & 0.020 \\
\hline Adiponectin & $\mu \mathrm{g} / \mathrm{mL}$ & $\begin{array}{l}2.860(1.813, \\
3.810)\end{array}$ & $\begin{array}{l}3.060(1.625, \\
4.253)\end{array}$ & $\mathrm{p}<0.001$ & $\begin{array}{l}4.150(3.205, \\
5.350)\end{array}$ & $\begin{array}{l}4.230(2.860, \\
6.220)\end{array}$ & $<0.001$ \\
\hline Myostatin & $\mathrm{pg} / \mathrm{mL}$ & $2,381.1 \pm 760.8$ & $2,980.0 \pm 1,088.9$ & 0.003 & $\begin{array}{l}2,377.5 \\
(1,751.1 \\
2,910.3)\end{array}$ & $\begin{array}{l}2,472.3 \\
(2,150.9 \\
3,472.3)\end{array}$ & 0.002 \\
\hline Leptin & $\mathrm{ng} / \mathrm{mL}$ & $21.2(15.4$ & $14.2(9.1,32.6)$ & 0.004 & $24.1(15.0$ & $15.0(7.4$ & $<0.001$ \\
\hline
\end{tabular}


Note: Results are expressed as mean \pm standard deviation or median (25\%, $75 \%$ quartile).

L group: Less than $5 \%$ of weight loss, $\mathrm{M}$ group: More than $5 \%$ of weight loss

\% of sex, diabetes mellitus, hypertension, and dyslipidemia are shown as percentage of the group members.

P value shows comparisons between pre- and post-intervention groups.

$* \mathrm{p}<0.05,{ }^{* *} \mathrm{p}<0.01,{ }^{* * *} \mathrm{p}<0.001$ for comparisons between less than $5 \%$ weight loss and more than $5 \%$ weight loss groups pre-intervention.

M, male; F, female; BMI, body mass index; \%fat, fat mass/weight $\times 100 ; \% L B M$, lean body mass/weight $\times 100$; VFA, visceral fat area; SFA, subcutaneous fat area; $\mathrm{AT}$, anaerobic threshold; $\mathrm{VO}_{2}$, oxygen consumption; baPWV, brachialankle pulse wave velocity; RHI, reactive hyperemia index; GLU, glucose; HbA1c, hemoglobin Alc; IRI, immunoreactive insulin; HOMA-IR, homeostasis model assessment-insulin resistance; HDL-c, high-density lipoprotein cholesterol; LDL-c, low-density lipoprotein cholesterol; TG, triglyceride; CRP, C-reactive protein.

Table 3. Correlation of changing weight, \% lean body mass, and myostatin with other parameters

\begin{tabular}{|c|c|c|c|c|c|c|}
\hline & \multicolumn{2}{|c|}{$\Delta \%$ LBM } & \multicolumn{2}{|c|}{$\Delta$ myostatin } & \multicolumn{2}{|c|}{$\Delta$ adiponectin } \\
\hline & $\mathbf{r}$ & p & $\mathbf{r}$ & p & $\mathbf{r}$ & p \\
\hline$\Delta$ Weight & -0.508 & 0.000 & 0.056 & 0.655 & -0.045 & 0.718 \\
\hline$\triangle \mathrm{BMI}$ & -0.484 & 0.000 & 0.075 & 0.547 & -0.061 & 0.626 \\
\hline$\Delta \%$ fat & -0.892 & 0.000 & 0.347 & 0.004 & -0.149 & 0.232 \\
\hline$\Delta \% \mathrm{LBM}$ & & & -0.359 & 0.003 & 0.102 & 0.413 \\
\hline$\triangle \mathrm{VFA}$ & -0.363 & 0.003 & -0.012 & 0.925 & 0.041 & 0.742 \\
\hline$\triangle \mathrm{SFA}$ & -0.519 & 0.000 & -0.101 & 0.421 & -0.092 & 0.463 \\
\hline$\Delta$ Peak $\mathrm{VO}_{2}$ & 0.315 & 0.011 & -0.101 & 0.423 & 0.022 & 0.862 \\
\hline$\Delta$ Handgrip & 0.048 & 0.709 & 0.072 & 0.577 & -0.253 & 0.047 \\
\hline$\triangle \mathrm{HOMA}$ & -0.162 & 0.194 & -0.024 & 0.848 & 0.079 & 0.531 \\
\hline$\Delta$ Myostatin & -0.359 & 0.003 & & & -0.250 & 0.043 \\
\hline$\triangle$ Adiponectin & 0.102 & 0.413 & -0.250 & 0.043 & & \\
\hline$\Delta$ Leptin & 0.010 & 0.938 & -0.114 & 0.362 & -0.087 & 0.487 \\
\hline$\Delta$ Irisin & 0.089 & 0.180 & -0.024 & 0.851 & -0.134 & 0.282 \\
\hline
\end{tabular}

Note: Values are expressed as correlation coefficients.

$\Delta$ signifies change in the corresponding quantity.

BMI, body mass index; \%fat, fat mass/weight $\times 100$; \%LBM, lean body mass/weight $\times 100$; VFA, visceral fat area; SFA, subcutaneous fat area; $\mathrm{VO}_{2}$, oxygen consumption; HOMA-IR, homeostasis model assessment-insulin resistance. 
Table 4. Stepwise multiple regression analysis of the changes in myostatin

\begin{tabular}{llll}
\hline & $\boldsymbol{\beta}$ & $\mathbf{p}$ value & VIF \\
\hline Sex & 0.110 & 0.388 & 1.051 \\
Age & -0.026 & 0.838 & 1.002 \\
Diabetes & -0.062 & 0.624 & 1.101 \\
$\Delta \%$ fat & 0.052 & 0.684 & 1.004 \\
$\Delta \%$ LBM & -0.095 & 0.454 & 1.000 \\
$\Delta$ Adiponectin & -0.262 & 0.035 & 1.000 \\
\hline
\end{tabular}

Note: $\beta$ : Standardized partial regression coefficient.

$\Delta$ signifies change in the corresponding quantity.

VIF, Variance inflation factor; \%fat, fat mass/weight $\times 100 ; \%$ LBM, lean body mass/weight ×100

\section{Figures}

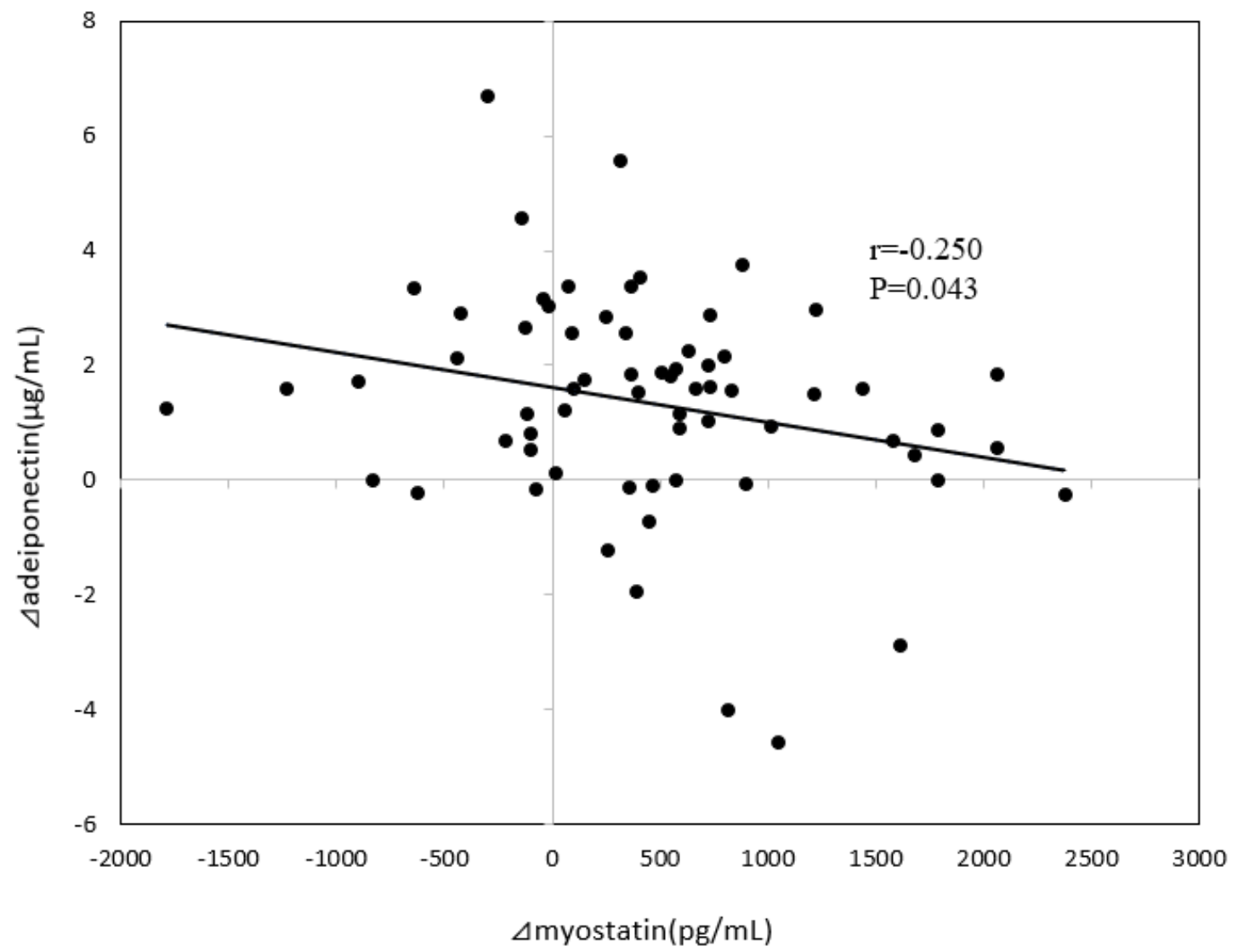

Figure 1

The correlation between change in myostatin and adiponectin. Note: We analyzed using the Spearman's rank correlation coefficient. 